\title{
Fertilitas dan Daya Tetas Ayam KUB Non Kaki Kuning dan Kaki Kuning di Balai Penelitian Temak Ciawi
}

\section{(The Fertility and Hatc hability of KUB Chicken Non Yellow Shank and Yellow Shank at Indonesian Research Institute for Animal Production)}

\author{
Pratiwi N, Sartika T \\ Balai Penelitian Ternak, PO Box 221, Bogor 16720 \\ nyu.pratiwi@gmail.com
}

\begin{abstract}
Fertility and hatchability are among the successes in the breeding program. Research conducted at the Indonesian Research Institute for Animal in poultry is one of them is KUB chicken (Kampung Unggul Badan Litbang Pertanian). This study aims to study the fertility and hatchability of KUB Non Yellow Shank (NK) and Yellow Shank (KK) chickens. The research method used is descriptive using primary and secondary data of 50 chickens KUB NK and KK. The eggs used are derived from the marriage of KUB chickens made using male sperm storage and then diluted for use by 4 females. The variables used are fertility and hatchability. The results of research on KUB KK chickens have an average fertility of $81.40 \pm 0.24 \%$ and hatchability of $69.54 \pm 0.34 \%$, while KUB NK chickens have an average fertility of $83.52 \pm 0.21 \%$ and power hatching $74.29 \pm 0.29 \%$. The fertility and hatchability of KUB NK and KK chickens did not show a significant difference. Both types of chicken show fertility and good hatchability, low hatchability which can be caused by environmental factors such as hatching machines and others.
\end{abstract}

Key words: Fertility, hatchability, KUB chicken

\begin{abstract}
ABSTRAK
Fertilitas dan daya tetas menjadi salah satu keberhasilan dalam program pembibitan. Penelitian yang dilakukan di Balai Penelitian Ternak pada unggas salah satunya adalah ayam KUB (Kampung Unggul Badan Litbang Pertanian). Penelitian ini bertujuan untuk mengetahui fertilitas dan daya tetas ayam KUB Non Kaki Kuning (NK) dan Kaki Kuning (KK). Metode penelitian yang digunakan adalah deskriptif dengan menggunakan data primer dan sekunder sebanyak 50 ekor ayam KUB NK dan KK. Telur yang digunakan berasal dari perkawinan Ayam KUB secara inseminasi buatan dengan melakukan penampungan sperma seekor pejantan secara segar kemudian diencerkan untuk digunakan 4 ekor betina. Variabel yang diamati adalah fertilitas dan daya tetas. Hasil penelitian pada ayam KUB KK memiliki rataan fertilitas $81,40 \pm 0,24 \%$ dan daya tetas $69,54 \pm 0,34 \%$, sedangkan ayam KUB NK memiliki rataan fertilitas $83,52 \pm 0,21 \%$ dan daya tetas $74,29 \pm 0,29 \%$. Fertilitas dan daya tetas ayam KUB NK dan KK tidak menunjukkan perbedaan yang signifikan. Kedua jenis ayam tersebut menunjukkan fertilitas dan daya tetas yang baik, rendahnya daya tetas dapat disebabkan oleh faktor lingkungan lain seperti mesin tetas dan lain-lain.
\end{abstract}

Kata kunci: Fertilitas, daya tetas, ayam KUB

\section{PENDAHULUAN}

Ayam lokal di Indonesia sangat beragam dan tersebar dari berbagai daerah. Penelitian yang dilakukan untuk membahas ayam lokal yang ada di Indonesia sangat 
banyak. Data tahun 2018 mencatat penyebaran ayam lokal di Indonesia, mulai dari Aceh (2\%), Sumatera Utara (5\%), Sumatera Barat (1\%), Riau (2\%), Jambi (5\%), Sumatera Selatan (3\%), Bengkulu (1\%), Lampung (4\%), Kepulauan Bangka Belitung (1\%), Jawa Barat (9\%), Jawa Tengah (14\%), DI Yogyakarta (1\%), Jawa Timur (12\%), Banten (4\%), Bali (1\%), Nusa Tenggara Barat (3\%), Nusa Tenggara Timur (3\%), Kalimantan Barat (2\%), Kalimantan Tengah (1\%), Kalimantan Selatan (3\%), Kalimantan Timur (2\%), Sulawesi Utara (1\%), Sulawesi Tengah (2\%), Sulawesi Selatan (10\%), Sulawesi Tenggara (3\%), Sulawesi Barat (1\%), Maluku (1\%), Papua (1\%) dengan total 310.959.951 ekor (BPS 2019). Ayam lokal merupakan hasil domestikasi dari ayam hutam merah (Gallus gallus) di setiap daerah, sehingga memiliki ciri khas yang beragam. Pengelompokan ayam lokal dibagi menjadi tipe petelur (wareng, kedu, merawang, dan nunukan), tipe pedaging (sedayu, pelung, gaok, dan nagrak) dan dwiguna (olangan, sentul, kampung, dan bangkalan) (Nataamijaya 2010).

Usaha yang dilakukan untuk meningkatkan produktivas ayam lokal di Indonesia belum maksimal dari berbagai aspek. Kendala yang dihadapi pada pengembangan ayam lokal juga memiliki masalah, yaitu sistem pemeliharaan masih tradisional, produktivitas rendah, baik produksi telur maupun daging, laju reproduksi, dan pertumbuhan. Selain kendala yang dihadapi, ayam lokal di Indonesia memiliki potensi yang baik, yaitu keragaman sifat fenotipe dan genotipe yang tinggi, adaptasi yang baik, tahan terhadap cekaman panas, dan tahan terhadap penyakit.

Hasil penelitian yang dilakukan oleh Iskandar \& Sartika (2014) di Balai Penelitian Ternak Ciawi (BALITNAK) menghasilkan ayam kampung unggul yang diberi nama ayam kampung Unggul Badan Litbang Pertanian (KUB). Ayam KUB adalah galur ayam yang sudah dilepas berdasarkan SK Mentan Nomor: 274/Kpts/SR.120/2/2014. Seleksi dilakukan secara terus menerus untuk mendapatkan ayam KUB dengan kualitas yang baik. Satu generasi ayam KUB memerlukan waktu selama 12-18 bulan, seleksi sudah dilakukan di Jawa Barat dan DKI selama 6 generasi. Ayam KUB digolongkan menjadi 2, yaitu ayam KUB Non Kaki Kuning (NK) dan Kaki Kuning (KK).

Fertilitas dan daya tetas adalah salah satu tolak ukur dalam keberlangsungan pembibitan. Persentase telur-telur yang memperlihatkan adanya perkembangan embrio dari telur yang ditetaskan tanpa memperhatikan telur tersebut menetas atau tidak dikatakan sebagai fertilitas (Sinabutar 2009). Daya tetas adalah persentase dari telur yang menetas dibandingkan dengan telur yang fertil (Dewanti et al. 2014). Daya tetas dan fertilitas ayam KUB dengan kawin alam dan inseminasi buatan memiliki nilai persentasi yang sama-sama baik. Berdasarkan laporan di atas, penelitian ini bertujuan untuk mengetahui fertilitas dan daya tetas ayam KUB Non Kaki Kuning (NK) dan Kaki Kuning (KK) di Balai Penelitian Ternak Ciawi.

\section{MATERI DAN METODE}

\section{Sampel penelitian}

Sampel yang digunakan dalam penelitian adalah 192 butir telur ayam KUB yang dikawinkan secara inseminasi buatan di Balai Penelitian Ternak Ciawi Bogor. Lokasi ini berada pada ketinggian 500 meter di atas permukaan laut dengan curah hujan rata-rata $3500-4000 \mathrm{~mm}$ per tahun, dan suhu rata-rata di lokasi ini adalah $22-28^{\circ} \mathrm{C}$ dengan kelembaban 79\%. Balai penelitian ternak Ciawi menggunakan mesin setter JPJ dengan kapasitas 8.000 butir dan mesin hatcher Aladin dengan kapasitas 4.000 ekor. 


\section{Metode}

Ayam KUB KK dan NK dipelihara dalam kandang baterai per individu, pemberian ransum yang digunakan untuk periode starter yaitu $\mathrm{Br} 21$ Sinta. Selama periode starter intensitas pemberian pakan dilakukan sebanyak satu kali sehari pada pukul 08.00 WIB. Pakan untuk periode grower menggunakan pakan ransum formulasi diberikan sebanyak 36-70 g/ekor/hari. Pemberian pakan layer hampir sama seperti periode grower dengan takaran 90-100 g/ekor/hari. Ayam KUB KK dan NK dikawinkan menggunakan teknik inseminasi buatan dengan mengkoleksi langsung semen pejantan dan kemudian di inseminasikan kepada betina, sex rasio yang digunakan adalah 1:4. Koleksi semen langsung dari pejantan sehingga hasil semen fresh dicampur dengan $\mathrm{NaCl}$ fisiologis $0,9 \%$. Semen yang sudah diencerkan, dimasukkan ke dalam syring ukuran $1 \mathrm{ml}$ sebanyak $0,2 \mathrm{ml}$ kemudian di inseminasikan ke satu ekor betina.

Penelitian menggunakan pola statistik dengan mengambil data langsung di Balai Penelitian Ternak Ciawi. Data ditabulasi dan dianalisis secara statistik. Data yang digunakan adalah fertilitas dan daya tetas telur ayam KUB NK dan KK. Analisis yang dilakukan adalah nilai rata-rata, standar deviasi, dan koefisien variasi.

Pengambilan telur dilakukan sebanyak 1 kali sehari kemudian telur yang dihasilkan dilakukan pencatatan, telur yang telah diambil langsung dimasukkan kedalam cooling room dengan suhu $18-22^{\circ} \mathrm{C}$ dan kelembaban $75-80 \%$ agar menjaga embrio tidak langsung berkembang. Pembersihan dilakukan pada telur tetas sebelum dimasukkan ke dalam mesin tetas menggunakan kain yang lembut. Mesin yang digunakan adalah jenis JPJ yaitu mesin tetas konvensional dengan pengaturan ventilasi udara digerakkan oleh kipas. Telurtelur yang sudah siap dimasukkan pada mesin setter dan setelah 3 hari dilakukan candling pertama dimana telur yang infertil dilakukan pencatatan. Selanjutnya telur tetas dilakukan candling ke-2 pada hari ke-10 dengan suhu mesin tetas $36-38^{\circ} \mathrm{C}$, kelembaban $65-70 \%$ dan pada hari ke-18 telur-telur dipindahkan ke mesin hatchery suhu berkisar $36-37^{\circ} \mathrm{C}$, kelembaban 67-80\%. yang telah diberikan sekat antara telur-telur dengan tetua yang berbeda. Setelah hari ke-21 telur-telur akan menetas dan dilakukan pencatatan telur yang menetas, tidak menetas atau yang sudah melakukan cracking.

Variabel yang diamati adalah fertilitas (\%) dengan cara mengitung jumlah telur yang fertil dibandingkan dengan telur yang disetting. Daya tetas (\%) dihitung dengan jumlah telur yang menetas dari jumlah telur yang fertil.

Perbandingan fertilitas (\%) dan daya tetas (\%) ayam KUB NK dan KK diuji secara statistik menggunakan Analysis of Variance (ANOVA) pada taraf nyata 95\%. dengan pengujian T-student (Steel \& Torrie 1991). Data diolah menggunakan program Minitab.

\section{HASIL DAN PEMBAHASAN}

Berdasarkan Tabel 1 diketahui bahwa rata-rata persentase fertilitas telur yang dihasilkan dari ayam KUB KK dan NK adalah 81,40\% dan 83,52\%. Koefisien variasi telur yang dihasilkan dari ayam KUB KK dan NK adalah 29,46\% dan 24,91\%. Data fertilitas telur ayam KUB KK dan NK yang dihasilkan secara keseluruhan memiliki persentase rendah dan beragam, karena nilai koefisien variasi yang dimiliki lebih dari 15\%. Populasi ternak dianggap seragam apabila memiliki koefisien variasi dibawah 15\%, semakin beragam dalam populasi yang akan diseleksi maka penerapan seleksi semakin efektif, sebaliknya semakin seragam dalam satu populasi apabila nilai koefisien variasi sangat kecil atau mendekati nol (0) maka seleksi semakin tidak efektif. 
Tabel 9. Fertilitas dan daya tetas ayam KUB KK dan NK

\begin{tabular}{lcccc}
\hline \hline \multirow{2}{*}{ Parameter } & \multicolumn{2}{c}{ Ayam KUB KK } & \multicolumn{2}{c}{ Ayam KUB NK } \\
\cline { 2 - 5 } & Rata-rata & Koefisien variasi & Rata-rata & Koefisien variasi \\
\hline Fertilitas (\%) & $81,40 \pm 0,24$ & 29,46 & $83,52 \pm 0,21$ & 24,91 \\
Daya tetas (\%) & $69,54 \pm 0,34$ & 48,41 & $74,29 \pm 0,29$ & 39,60 \\
\hline
\end{tabular}

Daya tetas telur ayam KUB KK dan NK memiliki rataan persentase sebesar 69,54\% dan 74,29\%. Koefisien variasi telur yang dihasilkan dari ayam KUB KK dan NK adalah 48,41\% dan 39,60\%. Hasil tersebut dikategorikan cukup tinggi, apabila dibandingkan daya tetas ayam kampung menurut Iriyanti et al. (2007) yaitu 72,02\% yang ditetaskan secara alami. Hasil daya tetas selama penelitian sudah optimal dibandingkan dengan daya tetas ayam Sentul menurut Nataamijaya et al. (1994) yaitu sebesar 78,20\% dan menurut Mansjoer et al. (1990) dan Nataamijaya (1993) daya tetas ayam sentul yaitu sebesar 80\%. Keberhasilan daya tetas dipengaruhi oleh berbagai macam faktor, faktor terpenting adalah mesin tetas. Suhu optimal dalam penetasan telur berkisar antara $36-37^{\circ} \mathrm{C}$ dan kelembaban berkisar antara 55-60\% untuk menetaskan telur ayam kampung.

Alur penetasan sudah baik, yaitu dengan sudah melakukan candling. Proses candling dilakukan untuk mengetahui embrio yang mati secara dini. Daya tetas dipengaruhi oleh banyak faktor, yaitu teknis pemilihan telur tetas atau seleksi telur tetas (bentuk telur, bobot telur, keadaan kerabang, warna kerabang dan lama penyimpanan) dan teknis operasional dari petugas yang menjalankan mesin tetas (suhu, kelembapan, sirkulasi udara dan pemutaran telur) serta faktor yang terletak pada induk yang digunakan sebagai bibit. Penyimpanan telur sebelum memasuki mesin tetas masih kurang baik penanganannya karena cooling room masih belum dirancang pada suhu $18-22^{\circ} \mathrm{C}$, tetapi telur yang akan ditetaskan memiliki masa simpan yang sudah baik yaitu kurang dar 7 hari dimana sesuai dengan pendapat Shanaway (1994) yaitu penyimpanan paling lama 1 minggu dengan temperatur optimum $16-18^{\circ} \mathrm{C}$.

\section{KESIMPULAN}

Fertilitas dan daya tetas ayam KUB NK dan KK tidak menunjukkan perbedaan yang signifikan. Kedua jenis ayam tersebut menunjukkan fertilitas dan daya tetas yang baik, rendahnya daya tetas dapat disebabkan oleh faktor lingkungan lain seperti mesin tetas dan lain-lain.

\section{DAFTAR PUSTAKA}

[BPS] Badan Pusat Statistik. 2019. Populasi ayam buras menurut provinsi. Jakarta (Indonesia): Badan Pusat Statistik.

Asmarawati W, Kustono, Widayanti DT, Bintara S, Ismayana. 2013. Pengaruh dosis sperma yang diencerkan dengan $\mathrm{NaCl}$ fisiologis terhadap fertilitas telur pada inseminasi buatan ayam kampung. Buletin Peternakan. 37:1-5.

Dewanti R, Yuhan, Sudiyono. 2014. Pengaruh bobot dan frekuensi pemutaran telur terhadap fertilitas, daya tetas dan bobot tetas itik lokal. Buletin Peternakan. 38:16-20.

Iriyanti N, Zuprizal Tri-Yuwanta, Keman S. 2007. Penggunaan vitamin E dalam pakan terhadap fertilitas, daya tetas dan bobot tetas telur ayam kampung. J Anim Prod. 9:36-39. 
Iskandar S, Sartika T. 2014. KUB chicken: The first Indonesia kampung chicken selected for egg production. Proceeding of the 16th AAAP Animal Science Congress Vol. II.

Kusmarahmat I. 1998. Pengaruh berbagai perbandingan jantan dan betina dalam kawin alam terhadap produksi, bobot, fertilitas dan daya tetas telur pada ayam kampung. Karya Ilmiah. Bogor (Indonesia): Fakultas Pertanian, Institusi Pertanian Bogor.

Mansjoer SS, Sikar SHS, Darwati S. 1990. Pencarian galur murni ayam kampung, ayam Pelung dan ayam Bangkok, dalam usaha pelestarian sumber genetik ayam di Indonesia. Bogor (Indonesia): Institut Pertanian Bogor.

Nataamijaya AG. 2010. Pengembangan potensi ayam lokal untuk menunjang peningkatan kesejahteraan petani. J Litbang Pertanian. 29:131-138.

Nataamijaya AG. 1993. Pengamatan terhadap status ayam Pelung, Nunukan, Kedu, Gaok dan Sentul, di pedesaan serta eksplorasi kemungkinan keberadaan ayam Buras langka lainnya. Prosiding Seminar Nasional Pengembangan Ternak Ayam Buras melalui Wadah Koperasi Menyongsong PJPT II. Bandung (Indonesia): Universitas Padjadjaran.

Nataamijaya AG, Dwiyanto K, Haryono, Sumantri E, Kusni M. 1994. Karakteristik morfologis delapan varietas Ayam bukan ras (Buras) langka. Prosiding Seminar Nasional Sains dan Teknologi Peternakan. Bogor (Indonesia): Pusat Penelitian dan Pengembangan Peternakan. hlm. 605-614.

Nataamijaya AG. 2008. Karakteristik dan produktivitas ayam kedu hitam. Buletin Plasma Nutfah. 14:85-89.

Nataamijaya AG, Setioko AR, Brahmantyo B, Dwiyanto K. 2003. Performans dan karakteristik tiga galur ayam lokal (Pelung, Arab, Sentul). Prosiding Seminar Nasional Teknologi Peternakan dan Veteriner. Bogor (Indonesia): Pusat Penelitian dan Pengembangan Peternakan. hlm. 353-359.

Rukmana R. 2003. Ayam buras intensifikasi dan kiat pengembangan. Cetakan ke-1. Yogyakarta (Indonesia): Kanisius.

Sinabutar M. 2009. Pengaruh frekuensi inseminasi buatan terhadap daya tetas telur itik lokal yang di inseminasi buatan dengan semen entok. Medan (Indonesia): Fakultas Pertanian, Universitas Sumatera Utara. 